\title{
Association between walking and strength of lower limbs after chronic stroke
}

\section{Associação entre velocidade de marcha e força de membros inferiores após acidente vascular encefálico crônico}

\author{
(D) Brenno Belchior Cordeiro Silva ${ }^{1}$, (D) Iza de Faria-Fortini², (D) Pollyana Helena Vieira Costa ${ }^{1}$, (D) Camila Torriani-Pasin ${ }^{3}$, (D) Janaine \\ Cunha Polese ${ }^{1}$
}

1 Department of Physical Therapy, Faculdade Ciências Médicas de Minas Gerais - FCMMG 2 Departament of Occupational Therapy, Faculdade Ciências Médicas de Minas Gerais FCMMG

3 School of Physical Education and Sports, Universidade de Sao Paulo - USP

Address for correspondence

Janaine Cunha Polese

E-mail: janainepolese@yahoo.com.br

Submitted: June 16, 2020

Accepted: November 17, 2020

Financing Source

PROBIC (Programa Institucional de Bolsas da Faculdade Ciências Médicas de Minas Gerais)

\section{How to cite}

Silva BBC, Faria-Fortini I, Costa PHV, TorrianiPasin C, Polese JC. Association between walking and strength of lower limbs after chronic stroke. Acta Fisiatr. 2020;27(3):131-138.

DOI: 10.11606/issn.2317-0190.v27i3a171118

\section{(c) (1) (2)}

\section{(C)2020 by Acta Fisiátrica}

This work is licensed under a Creative Commons Attribution 4.0 International

\begin{abstract}
Certain muscle groups strength directly influence walking speed (WS), and the lower strength of the paretic side is significantly associated with lower WS of individuals after stroke. Studies that have investigated the association between the average of lower limb strength and the WS in individuals are scarce. Therefore, it is important to determine whether the strength could explain walking performance due to some muscle weakness could be compensated by the strength of others, mainly because all muscles act in group, not isolated. Objective: To investigate the association between WS and lower limbs muscle strength, and to identify whether an individual muscle group or the average strength of lower limb would best predict WS and walking speed reserve (WSR) in individuals with stroke. Methods: Sixty-four community-dwelling individuals with chronic stroke have their maximum isometric strength (hip flexors/extensors/abductors, knee flexors/extensors, and ankle dorsiflexors/plantarflexors) and self-selected and fast WS (10m walk test) measured. WSR was considered as the difference between the fast and self-selected speed. Results: Average strength of the paretic limb accounted for $19 \%$ and $20 \%$ of the variance in self-selected and fast WS, respectively. Plantarflexor strength of the paretic, knee and hip flexors of the non-paretic side explained alone $27 \%$ of the WSR scores and plantarflexor strength of the paretic side alone explained $15 \%$. Conclusion: Average muscle strength of the paretic side contributed to self-selected and fast WS. Plantarflexor strength of the paretic side, knee and hip flexors of the non-paretic side contributed with the WSR of chronic stroke individuals.
\end{abstract}

Keywords: Stroke, Muscle Strength, Gait, Walking Speed

\section{RESUMO}

Estudos que investigam a associação entre a força média de membro inferior e a velocidade de marcha em indivíduos pós AVE são escassos. Logo, é importante determinar se a força muscular média pode explicar o desempenho na marcha, visto que os músculos agem em grupo. Objetivo: Investigar a associação entre velocidade de marcha e força muscular de membros inferiores, e identificar se um grupo muscular individual ou a força média de membros inferiores poderia predizer a velocidade de marcha e a velocidade de reserva (VR) em indivíduos pós AVE crônico. Métodos: 64 indivíduos deambuladores comunitários pós AVE crônico passaram por avaliação de força isométrica máxima (flexor/extensor/abdutor de quadril, flexor/extensor de joelho e flexor plantar/dorsoflexor de tornozelo) e velocidade de marcha habitual e máxima (Teste de Caminhada de 10 metros). A VR foi considerada a diferença entre velocidade de marcha máxima e habitual. Resultados: A força média do lado parético foi responsável por $19 \%$ e $20 \%$ da variância na velocidade de marcha habitual e máxima respectivamente. A força de flexor plantar do lado parético e flexor de quadril e joelho do lado não parético explicaram $27 \%$ da VR e força de flexor plantar do lado parético explicou $15 \%$. Conclusão: A força média do lado parético contribuiu para a velocidade de marcha habitual e máxima. A força de flexor plantar do lado parético, flexor de quadril e joelho do lado não parético contribuíram para a VR de indivíduos pós AVE crônico.

Palavras-chave: Acidente Vascular Cerebral, Força Muscular, Marcha, Velocidade de Caminhada 


\section{INTRODUCTION}

It is well established in the literature that muscle strength is a crucial variable and directly influence several outcomes, such as static and dynamic balance, ${ }^{1}$ cardiorespiratory fitness, ${ }^{1}$ and walking speed, ${ }^{1-4}$ when referring to individuals after stroke. It is reported that walking speed is the sixth functional vital sign, that is, powerful predictor of health-related outcomes. ${ }^{5,6}$

Community ambulation is a pre-requisite to a social participation for individuals after stroke since mobility ability is essential for carrying out daily activities and social roles, such community life, and recreational activities, directly or indirectly. ${ }^{7,8}$ Besides that, the return of community ambulation is the most important goal reported by individuals after stroke. ${ }^{9}$

Walking after stroke is usually marked by asymmetry that reduces the moment of plantarflexion, knee extension and hip flexion. ${ }^{10}$ In addition, these individuals produce lower torque of plantarflexors and high torque of hip flexors, when compared to healthy controls, which explains in part the reduced walking speed of this population. ${ }^{11}$ Muscle weakness is associated with gait performance in individuals after stroke, since the lower strength of the paretic side is significantly associated with lower walking speed of individuals. ${ }^{4,12}$

During clinical practice, assessment of muscle strength of the lower limbs is routinely performed. However, previous studies have only investigated the association between the strength of some specific muscle groups, mainly knee extensors, dorsiflexors, and plantarflexors, with walking speed. $1,2,4,5,11,13-17$

Studies in the literature that have investigated the association between average lower limb strength and the walking speed in individuals after stroke are scarce. Therefore, it would be also important to determine whether the average strength could explain walking performance due to some muscle weakness could be compensated by the strength of others, mainly because all muscles act in group, not isolated.

In addition, the literature is scarce about the association between muscle strength an individual's ability to increase their walking speed under specific demands of everyday activities and the environment, such as crossing a street safely and take public transport, for example.

This is an important issue, since individuals could increase their ability to walking speed and this fact allows individual to improve their social participation in activities that requires ambulation in the community. The ability to increase the walking speed according to the demand is described as walking speed reserve, which is calculated by the difference between fast and self-selected walking speed. ${ }^{18}$

\section{OBJECTIVE}

To investigate the association between walking speed and walking speed reserve and muscle strength of lower limbs, and to identify whether an individual muscle group or average limb strength would best predict self-selected and fast speed and walking speed reserve in individuals after stroke.

\section{METHODS}

This is an exploratory cross-sectional study, where the individuals were recruited in public rehabilitation centers and research contact lists. The outcome measures were randomly collected over one day in a laboratory setting.

\section{Participants}

The participants were included according the inclusion criteria: clinical diagnosis of primary or recurring stroke (at least 6 months since the onset after stroke); ${ }^{19} \geq 18$ years of age; and able to walk, with or without walking aids. Individuals were excluded if they had other clinical disabling conditions, and had cognitive impairments, which were screened by minimum score of 18 in the Mini Mental State Examination. ${ }^{20}$

\section{Procedures}

This study was approved by the institutional ethical review board and all participants provided written consent, prior to data collection. Before data collection, eligible participants were informed about the aims of the study and provided consent, based on previous approval from the ethics review board (CAAE: 58866416.0.0000.5134). Then, the participants underwent an interview and physical examination to characterize the sample. All data were collected in one day session (one hour and thirty minutes of duration) by trained personnel who had research experience in the area of stroke rehabilitation. The vital signs were monitored during all data collection.

After the initial procedures, demographic, clinical data, balance (Berg Balance Scale), and mobility (Timed Up and Go Test) were collected for sample characterization purposes. Berg Balance Scale is an objective measure that were composed by 14 items. Timed Up and Go Test start with the individual seated in a chair with his/her back at the chair back, and, with the command "go", the individual rises from the chair, walk 3 meters at fast speed without run, turn, walk back to the chair and sit. The time were measured by a chronometer.

\section{Outcome measures}

\section{Walking speed measurement}

The self-selected and fast walking speed (in $\mathrm{m} / \mathrm{s}$ ) was evaluated by means of the 10 meters Walk Test (10MWT) in which it was carried out in 14 meters, with two initial meters of acceleration and two final meters of deceleration. ${ }^{21}$

The time used to perform the 10MWT was timed once ${ }^{22}$ by using a cell phone timer, after verbal command for selfselected speed: "You will walk at the usual speed as if you are walking day by day", and for fast speed: "Walk as fast as possible and safely, but without running, to reach a bus which was about to pull out". ${ }^{23}$

At the end of the aisle a chair was placed where the individual could sit down after the test. Throughout the test one researcher walked alongside the individual to monitor their performance and minimize the risk of falling. The individual was allowed to use the usual assistive device during the test, including ankle stabilization devices (ankle foot orthosis - AFO), as they wish. The test present excellent test-retest reliability $(\text { ICC }=0.94)^{24}$ for individuals after stroke. Walking speed reserve was determined as the difference between the fast walking speed and self-selected walking speed. ${ }^{18}$ 


\section{Muscle strength measurements}

Muscle strength (in $\mathrm{mmHg}$ ) was assessed by the Modified Sphygmomanometer Test (MST), in an isometric contraction. ${ }^{25}$ A previous studies investigated the intra and inter-rater reliability, which presented adequate values ${ }^{25}$ and showed adequate reliability and validity, when compared against the hand-held dynamometer, for muscle strength measurements of individuals after stroke. ${ }^{26}$

Prior to the start of the test, the cuff was inflated to 100 $\mathrm{mmHg}$ and all the folds are removed and, then emptied to 20 $\mathrm{mmHg}$. The direction of the strength to be executed by the individual was demonstrated previously. The individual was also informed to maintain the maximum force strength for five seconds and the strength peak was recorded.

All tests were performed with the following verbal stimulus: "strength, strength, strength..." The measured muscle groups were hip flexors and extensors, hip abductors, knee flexors and extensors, and ankle dorsiflexors and plantarflexors. The positioning was standardized according to previous recommendations. ${ }^{27}$

The interval of one minute between each muscle group measurement was obeyed. Measurement was done once on both sides, always started measuring the non-paretic side. The manometer reading was done by a third researcher. ${ }^{27}$

The average strength of lower limbs was obtained by the sum of the muscle groups of each limb divided by the number of evaluated muscle groups.

\section{Statistical analyses}

The sample size of at least 60 participants was estimated, based upon formula proposed by Dohoo et al. ${ }^{28}$ For this calculation, five independent variables can be included in the multiple regression analyses.

Descriptive statistics (mean, SDs, ranges, and proportions), tests for normality (Kolmogorov-Smirnov), and equality of variances (Levene) were calculated for all outcomes. Pearson's correlation was used to evaluate the relationships (magnitude, direction, and significance) between walking speed (selfselected, fast, and ability to increase walking speed) and muscle strength (individual muscle group and average limb strength) variables.

Correlations are classified as very weak $(0.25)$, weak $(0.26$ $0.49)$, moderate (0.50-0.69), strong (0.70-0.89) and very strong $(0.90-1.00) .^{29}$ Stepwise multiple regression analysis was performed to identify which independent variables (muscle strength variables) would significantly predict three proposed models (self-selected, fast walking speed, and walking speed reserve). Variable entry for the regression was set at 0.05 , and removal was set at $0.10 .^{30,31}$

Prior to perform regression, the data were evaluated, to determine whether they fulfill all requirements for regression analyses, such as linearity, homoscedasticity, independence and normality of the residuals, as well as multicollinearity and outliers. $^{32}$

All analyses were carried-out with the SPSS software (version 17.0) with a significance level of $5 \%$. All analysis was performed by a researcher who was not involved in the data collection.

\section{RESULTS}

Eighty-five potential individuals were recruited by telephone, and nine did not meet the inclusion criteria (were not able to walk). Out of the 76 individuals, who agreed to participate, 12 did not show up, despite prior confirmation. Thus, the sample consisted of 64 individuals after stroke, 34 males, mean age of $59( \pm 16)$ years. Their mean self-select walking speed was $0.8( \pm 0.34) \mathrm{m} / \mathrm{s}$, whereas their fast walking speed was $1.00( \pm 0.42) \mathrm{m} / \mathrm{s}$, and walking speed reserve was $0.21( \pm 0.15) \mathrm{m} / \mathrm{s}$. The clinical and demographic characteristics of the participants are reported in Table 1.

Table 1. Clinical and demographic characteristics of the participants

\begin{tabular}{lc}
\hline Characteristics & $\mathbf{n = 6 4}$ \\
\hline Age (years), mean (SD) & $59(16)$ \\
Sex, $\mathrm{n}$ males (\%) & $34(57)$ \\
Time since the onset of the stroke (months), mean (SD) & $62(48)$ \\
Paretic side, right $\mathrm{n}(\%)$ & $51(80)$ \\
Type of stroke, $\mathrm{n}$ ischemic (\%) & $41(64)$ \\
Cognition (MMSE, 0-30), mean (SD) & $25(5)$ \\
Balance (BBS, 0-56), mean (SD) & $46(11)$ \\
Mobility (TUG, seconds), mean (SD) & $17(9)$ \\
\hline
\end{tabular}

SD: Standard deviation; MMSE: Mini-mental state examination; BBS: Berg Balance Scale; TUG: Timed Up and Go Test

As shown in table 2, on the paretic lower limb there was a reduction in muscle strength, when compared to the nonparetic lower limb, varying between $13.6 \%$ and $35.8 \%$.

Table 2. Descriptive statistics of measures of strength of the lower limb in individuals with chronic stroke $(n=64)$

\begin{tabular}{cc}
\hline Variable & Mean (SD) \\
\hline Hip extensors & \\
$\begin{array}{c}\text { paretic side (MST, } \mathrm{mmHg} \text { ), mean (SD) } \\
\text { non-paretic side (MST, } \mathrm{mmHg} \text { ), mean(SD) }\end{array}$ & $199.1(62.2)$ \\
$236.5(52.8)$
\end{tabular}

Hip flexors

paretic side (MST, mmHg), mean (SD) $149.8(48.2)$

Hip abductors non-paretic side (MST, mmHg), mean (SD) 186.7 (56.7)

paretic side (MST, $\mathrm{mmHg}$ ), mean (SD) 117.8 (43.5) non-paretic side (MST, mmHg), mean (SD) 145.9 (34.9)

Knee extensors

paretic side (MST, mmHg), mean (SD) 217.5 (58.8) non-paretic side (MST, $\mathrm{mmHg}$ ), mean (SD) 251.8 (47.2)

Knee flexors

paretic side (MST, mmHg), mean (SD) 137.5 (70.4) non-paretic side (MST, mmHg), mean (SD) 214.2 (56.6)

Ankle dorsiflexors

paretic side (MST, mmHg), mean (SD) 121.0 (67.7) non-paretic side (MST, mmHg), mean (SD) 182.5 (54.1)

Ankle plantarflexors

paretic side (MST, $\mathrm{mmHg}$ ), mean (SD) 131.8 (72.2)

non-paretic side (MST, mmHg), mean (SD) 191.2 (62.7) Average strength

paretic side (MST, mmHg), mean (SD) 153.5 (45.4) non-paretic side (MST, mmHg), mean (SD) 201.2 (38.7)

SD: Standard Deviation; MST: Modified Sphygmomanometer Test

Statistically significant and positive relationship of weak magnitudes $(0.32<r<0.43)$ were found between self-selected walking speed scores and all muscle groups and average 
strength of the paretic side, except between the hip extensors and ankle dorsiflexors, which was not statistic significant $(p=$ 0.05).

In addition, positive correlations of weak magnitudes were found between muscle strength of the non-paretic side, on following muscle groups: hip flexors $(r=0.36, p<0.0001)$ and abductors $(r=0.30, p=0.02)$, knee flexors $(r=0.30, p=0.02)$ and average strength $(r=0.32, p=0.01)$ and self-selected walking speed values (Table 3 ).

Within the fast walking speed, weak relationships ( $r=0.27$ 0.45 ) were found between fast walking speed scores and all muscle groups and average strength of the paretic side, except between the fast walking speed and hip extensors, which was not statistically significant $(r=0.26 ; p=0.05)$. In turn, positive correlations of weak magnitudes were found between muscle strength of the non-paretic side, only hip flexors ( $r=0.33 ; p=$ 0.01 ) and abductors $(r=0.27 ; p=0.04)$ (Table 3 ).

The walking speed reserve showed weak relationships only with ankle dorsiflexors $(r=0.30 ; p=0.02)$ and plantarflexors $(r=$ $0.38 ; p<0.0001$ ) of the paretic side (Table 3 ).

Table 3. Pearson correlation coefficients between selfselected, fast walking speed, walking speed reserve, and muscle strength in individuals with chronic stroke $(n=64)$

\begin{tabular}{lccc}
\hline & $\begin{array}{c}\text { Self- } \\
\text { selected } \\
\text { walking } \\
\text { speed }\end{array}$ & $\begin{array}{c}\text { Fast } \\
\text { walking } \\
\text { speed }\end{array}$ & $\begin{array}{c}\text { Walking } \\
\text { speed } \\
\text { reserve }\end{array}$ \\
\hline Hip extensors, paretic side & 0.25 & 0.26 & 0.15 \\
Hip extensors, non-paretic side & 0.13 & 0.10 & 0.05 \\
Hip flexors, paretic side & $0.35^{*}$ & $0.32^{* * *}$ & 0.04 \\
Hip flexors, non-paretic side & $0.36^{*}$ & $0.33^{* *}$ & 0.10 \\
Hip abductors, paretic side & $0.42^{*}$ & $0.44^{*}$ & 0.20 \\
Hip abductors, non-paretic side & $0.30^{* * *}$ & $0.27^{* * * *}$ & 0.09 \\
Knee extensors, paretic side & $0.34^{*}$ & $0.27^{* * * *}$ & 0.02 \\
Knee extensors, non-paretic side & 0.14 & 0.09 & 0.13 \\
Knee flexors, paretic side & $0.32^{* *}$ & $0.35^{*}$ & 0.19 \\
Knee flexors, non-paretic side & $0.30^{* * *}$ & 0.16 & 0.24 \\
Ankle dorsiflexors, paretic side & 0.25 & $0.31^{* * *}$ & $0.30^{* * *}$ \\
Ankle dorsiflexors, non-paretic side & 0.19 & 0.17 & 0.06 \\
Ankle plantarflexors, paretic side & $0.36^{*}$ & $0.43^{*}$ & $0.38^{*}$ \\
Ankle plantarflexors, non-paretic side & 0.22 & 0.20 & 0.04 \\
Average strength, paretic side & $0.43^{*}$ & $0.45^{*}$ & 0.25 \\
Average strength, non-paretic side & $0.32^{* *}$ & 0.26 & -0.03 \\
\hline H & & &
\end{tabular}

${ }^{*} p<0.0001 ;{ }^{* *} p=0.01 ;{ }^{* * *} p=0.02 ;{ }^{* * * *} p=0.04$

For the self-select walking speed model, the regression analysis revealed that the average muscle strength of the paretic side alone explained $19 \%(F=13.16 ; p<0.01)$ of the variance. This variable was positively correlated with self-select walking speed, indicating that individuals who had higher average muscle strength to have higher self-select walking speed (Table 4).

For the fast walking speed model, the regression analysis revealed that the average muscle strength of the paretic side alone explained $20 \%(F=13.35 ; p<0.01)$ of the variance. This variable was positively correlated with fast walking speed, indicating that individuals who had higher average muscle strength to have higher fast walking speed (Table 4). For walking speed reserve model the regression analysis revealed that the three predictors (ankle plantaflexor of the paretic side, knee flexor of the non-paretic side and hip flexor of the nonparetic side) were retained (Table 4).

The ankle plantarflexor of the paretic side alone explained $15 \%(F=9.28, p<0.01)$ of the variance in the walking speed reserve scores. When knee flexor of the non-paretic side was included in the model, the explained variance increased to $21 \%$ $(F=7.03, p<0.01)$. By adding hip flexor of the non-paretic side, the variance increased to $27 \%(F=6.33, p<0.01)$.

All variables were positively correlated with walking speed reserve, indicating that individuals who had higher muscle strength to have higher ability to increase walking speed (Table 4).

\section{DISCUSSION}

The results of the present study indicate muscle strength of some lower limb muscle groups have association with selfselected, fast and walking speed reserve in individuals after stroke. In addition, average muscle strength of the paretic side explained $19 \%$ of variance for self-selected speed, and $20 \%$ of variance for fast speed. Ankle plantarflexor muscle strength of the paretic side explained alone $15 \%$ of the walking speed reserve of individuals after stroke. Knee and hip flexors of the non-paretic each added $6 \%$ on the model.

Measures of walking speed are recognized as indicators of functional performance, independence, quality of life, and social participation. ${ }^{3,33-36}$

The relationship between muscle strength of paretic lower limb and walking speed in individuals with stroke was previously investigated. ${ }^{1,4,12}$ A previous systematic review ${ }^{12}$ investigated the association between isometric strength with self-select and fast walking speed after stroke. The study found that all investigated muscle groups have association (poor to strong) with walking speed: paretic hip flexors ( $r=0.25-0.82)$, hip extensors ( $r=0.29-0.78)$, hip abductors $(r=0.24-0.80)$, knee extensors ( $r=0.18-0.81)$, knee flexors $(r=0.30-0.83)$, ankle plantarflexors ( $r=0.11-0.83)$, ankle dorsiflexors ( $r=0.50-0.77)$, hip adductors ( $r=0.29)$, hip internal rotators $(r=0.30)$, hip external rotators $(r=0.22)$, ankle invertors $(r=0.25)$ and ankle evertors $(r=0.33)$. The non-paretic limb showed poor to moderate correlations for each muscle group $(r=0.05-0.70){ }^{12}$

When compared to previous studies, it is observed similar results to those reported by Dorsch et al. ${ }^{4}$ These authors analyzed this association in a sample of individuals with chronic stroke ( $>1$ year after stroke).

The results showed maximum isometric strength of various muscle groups were positively associated $(0.27<r<0.50)$ with self-selected walking speed, with weak magnitude correlation values. This fact can be explained by a greater number of factors that influence in the walking speed, such as lower limb coordination, ${ }^{37}$ balance ${ }^{38}$ and cardiorespiratory fitness. ${ }^{22}$

However, divergent results were found to those reported by Aguiar et al. ${ }^{1}$ These authors investigated the association between muscle strength of trunk and lower limbs with selfselected and fast walking speed in individuals after sub-acute stroke (3-6 months after stroke).

They found positively association between self-selected (0.29-0.43) and fast (0.37-0.59) walking speed and all 12 investigated group muscles, except for knee flexors of nonparetic side $(r=0.29 ; p=0.06) .^{1}$ 
Table 4. Results of regression analysis for self-select, fast and walking speed reserve in individuals with chronic stroke ( $\mathrm{n}=64)$

\begin{tabular}{|c|c|c|c|c|}
\hline Variable & B $(95 \% \mathrm{Cl})$ & $\boldsymbol{\beta}$ & $\mathbf{R 2}$ & SEE \\
\hline \multicolumn{5}{|l|}{ Self-selected walking speed } \\
\hline \multicolumn{5}{|l|}{ Step 1} \\
\hline Constant & $0.31 \pm 0.14(0.02$ to 0.59$)$ & - & - & \\
\hline Average muscle strength of the paretic side & $0.01 \pm 0.02$ (0.01 to 0.05$)$ & 0.43 & 0.19 & 0.35 \\
\hline \multicolumn{5}{|l|}{ Fast walking speed } \\
\hline \multicolumn{5}{|l|}{ Step 1} \\
\hline Constant & $0.38 \pm 0.19(0.02$ to 0.74$)$ & - & - & - \\
\hline Average muscle strength of the paretic side & $0.04 \pm 0.01$ (0.02 to 0.61$)$ & 0.45 & 0.20 & 0.38 \\
\hline \multicolumn{5}{|l|}{ Walking speed reserve } \\
\hline \multicolumn{5}{|l|}{ Step 1} \\
\hline Constant & $0.10 \pm 0.04$ (0.03 to 0.18$)$ & - & - & - \\
\hline Ankle plantarflexor of the paretic side & $0.01 \pm 0.01$ (0.01 to 0.02$)$ & 0.39 & 0.15 & 0.13 \\
\hline \multicolumn{5}{|l|}{ Step 2} \\
\hline Constant & $0.24 \pm 0.08$ (0.09 to 0.39$)$ & - & - & - \\
\hline Ankle plantarflexor of the paretic side & $0.01 \pm 0.01$ (0.01 to 0.02$)$ & 0.39 & - & - \\
\hline Knee flexor of the non-paretic side & $-0.01 \pm 0.01(0.01$ to 0.02$)$ & -0.25 & 0.21 & 0.13 \\
\hline \multicolumn{5}{|l|}{ Step 3} \\
\hline Constant & $0.19 \pm 0.08$ (0.04 to 0.35$)$ & - & - & - \\
\hline Ankle plantarflexor of the paretic side & $0.01 \pm 0.01$ (0.01 to 0.02$)$ & 0.36 & - & - \\
\hline Knee flexor of the non-paretic side & $-0.01 \pm 0.01(0.01$ to 0.02$)$ & -0.41 & - & - \\
\hline Hip flexor of the non-paretic side & $0.01 \pm 0.01$ (0.01 to 0.03$)$ & 0.29 & 0.27 & 0.12 \\
\hline
\end{tabular}

B: Regression coefficients, followed by the respective standard error; Cl: Confidence interval; 6: Standardized regression coefficient; R2: Coefficient of determination; SEE: Standard error of the estimate

In the present study, it was observed that only approximately $50 \%$ of the evaluated muscle groups were correlated with self-selected and fast walking speed, while Aguiar et al. ${ }^{1}$ reported a correlation among almost all muscle groups evaluated and the usual and fast gait speed.

The difference between these findings could be related to the phase after stroke, since during chronic phase the pattern of walking is well stablished and presents compensation features, reducing the contribution of some muscular groups during the walking.

The regression model showed average strength of the paretic side explains $19 \%$ and $20 \%$ of the variance of the selfselected and fast walking speed, respectively. In addition, it was also observed the walking speed reserve can be explained by the strength of paretic plantarflexors (15\%), knee (6\%), and hip flexors of the non-paretic side (6\%). In the previous studies that performed regression analyses to identify the lower limb muscle group that would predict walking speed after stroke, the paretic ankle dorsiflexors appeared as the main explanatory variable. ${ }^{1,4}$

Dorsch et al. ${ }^{4}$ demonstrated that ankle dorsiflexors of the paretic side accounted for $31 \%$ of the variance in self-selected walking speed $(p<0.001),{ }^{4}$ while Aguiar et al. ${ }^{1}$ demonstrated that $29 \%(p=0.002)$ of fast speed can be explained by the strength of dorsiflexors of the non-paretic side.

These results are not in agreement with the findings of the present study, which found that average strength of the paretic side predict self-selected and fast walking speed in individuals with chronic stroke.

The differences could be explained by the fact that previous studies that performed regression analyses assessed only the contribution of isolated muscle groups, without concomitantly considering the combined contribution of all paretic and nonparetic lower limb muscle groups to the ability of the individual to walking.
Additionally, it is necessary to consider the phase of evolution after the occurrence of stroke. The time after stroke allows compensatory adaptation for movements and activities. ${ }^{39,40}$ Possibly the individuals in the sub-acute phase are re-adjusting their gait pattern in order to achieve a state of optimal metabolic efficiency, for example. On the other hand, during chronic phase the individuals are already adapted to the physical demands, so they used the expected muscle group to produce the major power during gait, i.e., plantarflexors. ${ }^{41-43}$

The literature is scarce about the factors related to ability to increase walking speed. In our study the walking speed reserve was $20 \%$, which is slightly lower than previous studies, ${ }^{44,45}$ described between 25 to $50 \%$ in ambulatory after stroke with similar walking speed, and age (mean self-selected walking speed between $0.74 \mathrm{~m} /$ and $0.84 \mathrm{~m} / \mathrm{s}$, and mean fast walking speed between $0.93 \mathrm{~m} / \mathrm{s}$ to $1.05 \mathrm{~m} / \mathrm{s}$; mean age ranged 60 to 61 years). ${ }^{44,45}$

One previous study found a significant association between balance (assessed by Berg Balance Scale) and walking speed reserve $(r=0.74)$ in individuals after stroke, demonstrating that besides muscle strength other variables may be related to ability to increase gait speed. As best of our knowledge, this is the first study to found plantarflexor muscle strength of the paretic side is the major responsible of the walking speed reserve. This result is in line with the literature reporting the role of plantarflexors power during push-off as the main predictor of walking speed. ${ }^{41-43}$

The results of present study have important clinical implications. Previous studies have investigated the individual role of muscles groups in predicting the walking speed. ${ }^{4,44,46-48}$ However, the relation between average strength of paretic side on walking speed and walking speed reserve was not well reported so far. Individuals after stroke show different strategies to activate the lower limb muscles to walk during self-selected, fast and, to increase walking speed. Thus, the 
evaluating, and possibly strengthening, should be addressed for the total paretic side, not only to specific muscle groups, since the residual deficits of the lower limbs were the physical variable impairment that best predict participation in daily activity $\left(r^{2}=22 \% ; p<0.0001\right)$ and social role domains $\left(r^{2}=16 \%\right.$; $\mathrm{p}<0.0001)$ of the social participation in individuals after stroke. ${ }^{8}$

Thus, the average lower limb strength training can be an strategy to in order to increase speed, and consequently, enhance social participation within home and community environment, when the ability to manage complex environmental demands is required, for example to crossing the street before traffic light changes and getting on and off buses and subways.

\section{Limitations of the study}

Although it was observed previously that trunk and upper limb strength of individuals after stroke could influence on force transmission during the walking, we did not address these issues. Therefore, the interaction between upper limbs and trunk with lower limb strength was not accessed in this study.

Our results are valid for chronic, ambulators, mild/moderate physical limitations, preserved cognitive, and capable to communicate, limiting the external validity of the findings. The statistical analyses used do not allow interpretation related to causality between variables.

Although it is well established in the literature that each muscle group contributes differently during daily activities performance, it is not possible to transfer this level of contribution to this population, since each individual use a different strategy of movement, for example. Also, the use of ankle foot orthosis was not controlled.

Finally, factors as balance, coordination, cardiorespiratory fitness, and other outcomes could explain the remaining variance of the independent variables. Future studies should include other variables in the model beyond the muscle strength.

\section{CONCLUSION}

The results of the present study indicated muscle strength of the lower limbs have significant association with selfselected, fast walking speed and, walking speed reserve. It was observed average muscle strength of the paretic side explained $19-20 \%$ of the variance of self-selected and fast walking speed, respectively. It was found plantarflexor muscle strength of the paretic side explained alone $15 \%$ of ability to increase walking speed of individuals after chronic stroke. When knee and hip flexors of the non-paretic side were included in the model, the explained variance increased to $27 \%$.

\section{REFERENCES}

1. Aguiar LT, Camargo LBA, Estarlino LD, Teixeira-Salmela LF, Faria CDCM. Strength of the lower limb and trunk muscles is associated with gait speed in individuals with sub-acute stroke: a cross-sectional study. Braz J Phys Ther. 2018;22(6):459-66.

https://doi.org/10.1016/j.bjpt.2018.03.001
2. Teixeira-Salmela LF, Olney SJ, Nadeau S, Brouwer B. Muscle strengthening and physical conditioning to reduce impairment and disability in chronic stroke survivors. Arch Phys Med Rehabil. 1999;80(10):1211-8. Doi: https://doi.org/10.1016/s0003-9993(99)90018-7

3. Flansbjer UB, Downham D, Lexell J. Knee muscle strength, gait performance, and perceived participation after stroke. Arch Phys Med Rehabil. 2006;87(7):974-80. Doi: https://doi.org/10.1016/j.apmr.2006.03.008

4. Dorsch S, Ada L, Canning CG, Al-Zharani M, Dean C. The strength of the ankle dorsiflexors has a significant contribution to walking speed in people who can walk independently after stroke: an observational study. Arch Phys Med Rehabil. 2012;93(6):1072-6. Doi: https://doi.org/10.1016/j.apmr.2012.01.005

5. Middleton A, Fritz SL, Lusardi M. Walking speed: the functional vital sign. J Aging Phys Act. 2015;23(2):314-22. Doi: https://doi.org/10.1123/japa.2013-0236

6. Lusardi MM. Using walking speed in clinical practice: interpreting age-, gender-, and function-specific norms. Top Geriatr Rehabil. 2012;28(2):77-90. Doi: https://doi.org/10.1097/TGR.0b013e31823d7b9

7. Faria-Fortini I, Basílio ML, Polese JC, Menezes KKP, Faria CDCM, Scianni AA, et al. Caracterização da participação social de indivíduos na fase crônica pós-acidente vascular encefálico. Rev Ter Ocup Univ São Paulo. 2017;28(1):71-8. Doi: https://doi.org/10.11606/issn.2238-6149.v28i1p71-78

8. Faria-Fortini I, Basílio ML, Polese JC, Menezes KKP, Faria $\mathrm{CDCM}$, Scianni AA, et al. Strength deficits of the paretic lower extremity muscles were the impairment variables that best explained restrictions in participation after stroke. Disabil Rehabil. 2017;39(21):2158-63. Doi: https://doi.org/10.1080/09638288.2016.1219397

9. Lord SE, Rochester L. Measurement of community ambulation after stroke: current status and future developments. Stroke. 2005;36(7):1457-61. Doi: https://doi.org/10.1161/01.STR.0000170698.20376.2e

10. Lauzière $S$, Miéville $C$, Betschart $M$, Aissaoui $R$, Nadeau S. Plantarflexor weakness is a determinant of kinetic asymmetry during gait in post-stroke individuals walking with high levels of effort. Clin Biomech (Bristol, Avon). 2015;30(9):946-52.

https://doi.org/10.1016/i.clinbiomech.2015.07.004

Doi:

11. Nadeau S, Gravel D, Arsenault AB, Bourbonnais D. Plantarflexor weakness as a limiting factor of gait speed in stroke subjects and the compensating role of hip flexors. Clin Biomech (Bristol, Avon). 1999;14(2):125-35. Doi: https://doi.org/10.1016/S0268-0033(98)00062-X

12. Mentiplay BF, Adair B, Bower KJ, Williams G, Tole G, Clark RA. Associations between lower limb strength and gait velocity following stroke: A systematic review. Brain Inj. 2015;29(4):409-22.

Doi: https://doi.org/10.3109/02699052.2014.995231

13. Bohannon RW. Strength of lower limb related to gait velocity and cadence in stroke patients. Physiother Can. 1986;38(4):204-6. Doi: https://doi.org/10.3138/ptc.38.4.204

14. Nakamura R, Watanabe S, Handa T, Morohashi I. The relationship between walking speed and muscle strength for knee extension in hemiparetic stroke patients: a follow-up study. Tohoku J Exp Med. 1988;154(2):111-3. Doi: https://doi.org/10.1620/tjem.154.111 
15. Lindmark B, Hamrin E. Relation between gait speed, knee muscle torque and motor scores in post-stroke patients. Scand J Caring Sci. 1995;9(4):195-202. Doi: https://doi.org/10.1111/i.1471-6712.1995.tb00414.x

16. Bohannon RW. Gait performance of hemiparetic stroke patients: selected variables. Arch Phys Med Rehabil. 1987;68(11):777-81.

17. Bohannon RW. Muscle strength and muscle training after stroke. J Rehabil Med. 2007;39(1):14-20. Doi: https://doi.org/10.2340/16501977-0018

18. Middleton $\mathrm{A}$, Braun $\mathrm{CH}$, Lewek MD, Fritz SL. Balance impairment limits ability to increase walking speed in individuals with chronic stroke. Disabil Rehabil. 2017;39(5):497-502.

Doi:

https://doi.org/10.3109/09638288.2016.1152603

19. Bernhardt J, Hayward KS, Kwakkel G, Ward NS, Wolf SL, Borschmann $\mathrm{K}$, et al. Agreed definitions and a shared vision for new standards in stroke recovery research: the stroke recovery and rehabilitation roundtable taskforce. Int J Stroke. 2017;12(5):444-50.

Doi:

https://doi.org/10.1177/1747493017711816

20. Bertolucci PH, Brucki SMD, Campacci SR, Juliano Y. O miniexame do estado mental em uma população geral: impacto da escolaridade. Arq Neuropsiquiatr. 1994;52(1):1-7. Doi: https://doi.org/10.1590/S0004-282X1994000100001

21. Salbach NM, Mayo NE, Higgins J, Ahmed S, Finch LE, Richards $\mathrm{CL}$. Responsiveness and predictability of gait speed and other disability measures in acute stroke. Arch Phys Med Rehabil. 2001;82(9):1204-12.

https://doi.org/10.1053/apmr.2001.24907

22. Faria CD, Teixeira-Salmela LF, Neto MG, Rodrigues-de-Paula F. Performance-based tests in subjects with stroke: outcome scores, reliability and measurement errors. Clin Rehabil. 2012;26(5):460-9.

Doi:

https://doi.org/10.1177/0269215511423849

23. Nascimento LR, Caetano LC, Freitas DC, Morais TM, Polese JC, Teixeira-Salmela LF. Different instructions during the tenmeter walking test determined significant increases in maximum gait speed in individuals with chronic hemiparesis. Rev Bras Fisioter. 2012;16(2):122-7. Doi: https://doi.org/10.1590/S1413-35552012005000008

24. Flansbjer UB, Holmbäck AM, Downham D, Patten C, Lexell J. Reliability of gait performance tests in men and women with hemiparesis after stroke. J Rehabil Med. 2005;37(2):75-82. Doi: https://doi.org/10.1080/16501970410017215

25. Souza LA, Martins JC, Teixeira-Salmela LF, Lara EM, Moura JB, Aguiar LT, et al. Validity and reliability of the modified sphygmomanometer test to assess strength of the lower limbs and trunk muscles after stroke. J Rehabil Med. 2014;46(7):620-8. Doi: https://doi.org/10.2340/16501977$\underline{1823}$

26. Aguiar LT, Martins JC, Brito SAF, Mendes CLG, TeixeiraSalmela LF, Faria CDCDM. Knee extensor muscles strength indicates global lower-limb strength in individuals who have suffered a stroke: a cross-sectional study. Braz J Phys Ther. 2019;23(3):221-7.

Doi: https://doi.org/10.1016/j.bjpt.2018.08.001

27. Castro LA, Martins JC, Teixeira-Salmela LF, Godoy MR, Aguiar LT, Faria CDCM. Avaliação da força muscular pelo teste do esfigmomanômetro modificado: uma revisão da literatura. Fisioter Mov. 2017; 26(2):437-52. Doi https://doi.org/10.1590/S0103-51502013000200021
28. Audigé L. Veterinary epidemiologic research: I. Dohoo, W. Martin, H. Stryhn, Atlantic Veterinary College, Charlottetown, PE, Canada, 2003. Prev Vet Med. 2005;68(24):289-92.

https://doi.org/10.1016/i.prevetmed.2004.11.001

29. Munro BH. Statistical methods for health care research. $6^{\text {th }}$ ed. New York: Lippincott Williams \& Wilkins; 2005.

30. Draper NR, Smith H. Applied regression analysis. $3^{\text {rd }}$ ed. New York: Wiley; 1998.

31. Montgomery DC, Peck EA. Introduction to linear regression analysis. $2^{\text {nd }}$ ed. New York: J. Wiley; 1992.

32. Portney LG, Watkins MP. Foundations of clinical research: applications to practice. $3^{\text {rd }}$ ed. Upper Saddle River: PrenticeHall; 2009.

33. Teixeira-Salmela LF, Lima RCM, Lima LAO, Morais SG, Goulart F. Assimetria e desempenho funcional em hemiplégicos crônicos antes e após programa de treinamento em academia. Rev Bras Fisioter. 2005;9(2):227-33.

34. Khanittanuphong $P$, Tipchatyotin $S$. Correlation of the gait speed with the quality of life and the quality of life classified according to speed-based community ambulation in Thai stroke survivors. NeuroRehabilitation. 2017;41(1):135-41. Doi: https://doi.org/10.3233/NRE-171465

35. Faria-Fortini I, Basílio ML, Scianni AA, Faria CDCM, TeixeiraSalmela LF. Performance and capacity-based measures of locomotion, compared to impairment-based measures, best predicted participation in individuals with hemiparesis due to stroke. Disabil Rehabil. 2018;40(15):1791-8. Doi: https://doi.org/10.1080/09638288.2017.1312570

36. Grau-Pellicer M, Chamarro-Lusar A, Medina-Casanovas J, Serdà Ferrer BC. Walking speed as a predictor of community mobility and quality of life after stroke. Top Stroke Rehabil. 2019;26(5):349-58.

https://doi.org/10.1080/10749357.2019.1605751

37. Kwan MS, Hassett LM, Ada L, Canning CG. Relationship between lower limb coordination and walking speed after stroke: an observational study. Braz J Phys Ther. 2019;23(6): 527-31. Doi: https://doi.org/10.1016/j.bjpt.2018.10.006

38. Madhavan S, Bishnoi A. Comparison of the mini-balance evaluations systems test with the berg balance scale in relationship to walking speed and motor recovery post stroke. Top Stroke Rehabil. 2017;24(8):579-84. Doi: https://doi.org/10.1080/10749357.2017.1366097

39. Jones TA. Motor compensation and its effects on neural reorganization after stroke. Nat Rev Neurosci. 2017;18(5):267-80.

https://doi.org/10.1038/nrn.2017.26

Doi:

40. Levin MF, Kleim JA, Wolf SL. What do motor "recovery" and "compensation" mean in patients following stroke? Neurorehabil Neural Repair. 2009;23(4):313-9. Doi: https://doi.org/10.1177/1545968308328727

41. Polese JC, Teixeira-Salmela LF, Nascimento LR, Faria CD, Kirkwood RN, Laurentino GC, et al. The effects of walking sticks on gait kinematics and kinetics with chronic stroke survivors. Clin Biomech (Bristol, Avon). 2012;27(2):131-7. Doi: https://doi.org/10.1016/i.clinbiomech.2011.08.003

42. Teixeira-Salmela LF, Nadeau S, Mcbride I, Olney SJ. Effects of muscle strengthening and physical conditioning training on temporal, kinematic and kinetic variables during gait in chronic stroke survivors. J Rehabil Med. 2001;33(2):53-60. Doi: https://doi.org/10.1080/165019701750098867 
43. Winter DA. The biomechanics and motor control of human gait: normal, elderly and pathological. $2^{\text {nd }}$ ed. Wateloo: Waterloo Biomechanics; 1991.

44. Ng SS, Au KK, Chan EL, Chan DO, Keung GM, Lee JK, et al. Effect of acceleration and deceleration distance on walking speed of people with chronic stroke. J Rehabil Med. 2016;48(8):666-70. Doi: https://doi.org/10.2340/165019772124

45. Dobkin BH. Short-distance walking speed and timed walking distance: redundant measures for clinical trials? Neurology. 2006;66(4):584-6.

Doi: https://doi.org/10.1212/01.wnl.0000198502.88147.dd

46. Lin PY, Yang YR, Cheng SJ, Wang RY. The relation between ankle impairments and gait velocity and symmetry in people with stroke. Arch Phys Med Rehabil. 2006;87(4):562-8. Doi: https://doi.org/10.1016/j.apmr.2005.12.042
47. Mentiplay BF, Williams G, Tan D, Adair B, Pua YH, Bok CW, et al. Gait Velocity and joint power generation after stroke: contribution of strength and balance. Am J Phys Med Rehabil. 2019;98(10):841-9.

Doi: https://doi.org/10.1097/PHM.0000000000001122

48. Nasciutti-Prudente C, Oliveira FG, Houri SF, de Paula Goulart FR, Neto MH, Teixeira-Salmela LF. Relationships between muscular torque and gait speed in chronic hemiparetic subjects. Disabil Rehabil. 2009;31(2):103-8. Doi: https://doi.org/10.1080/09638280701818055 